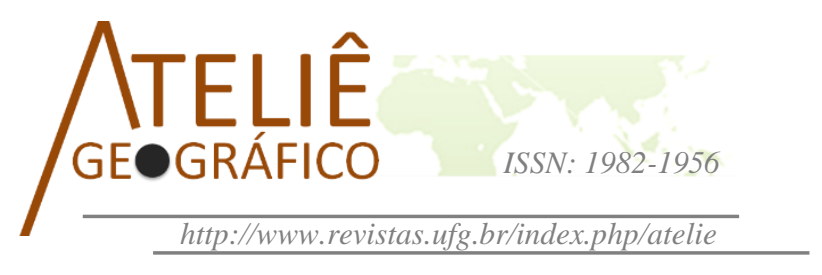

\title{
Las disparidades entre las cargas de dependencia demográficas provinciales. Argentina (1914-2040)
}

\author{
Disparities between burdens of demographical provincial \\ dependence. Argentina (1914-2040)
}

\section{As disparidades entre as cargas demográficas de dependência provincial. Argentina (1914-2040)}

Fernando Ariel Manzano

Universidad Nacional del Centro de la Provincia de Buenos Aires fernandoarielmanzano@fch.unicen.edu.ar

\begin{abstract}
Resumen
Se parte de la explicación de las tendencias poblacionales caracterizada en la teoría de la transición demográfica que establece un patrón de cambios en natalidad y mortalidad que conlleva inevitablemente en todas las sociedades a una ventana temporal con mínima carga de dependencia demográfica. A partir del análisis de los datos censales a nivel provincial en Argentina durante el periodo 1914-2040, se visibilizan situaciones en las cuales la carga de dependencia demográfica se caracteriza por marcadas divergencias interprovinciales. Existen provincias que inician el periodo bajo estudio con baja carga de dependencia demográfica, y se mantienen en estas posiciones a lo largo del tiempo, mientras que en otras se desvanecen las ventajas relativas iniciales, en cambio las restantes provincias sobrellevan continuamente los efectos de este desequilibrio demográfico. La hipótesis es que la ausencia del componente migratorio es la limitación principal para explicar estas supuestas irregularidades por parte la teoría demográfica. Se presenta la relación entre los valores de la relación de dependencia demográfica provinciales y los flujos migratorios según años censales.
\end{abstract}

Palabras clave: carga demográfica; migraciones; estructura de edades; teoría de la transición demográfica.

\begin{abstract}
This article is based on the explanation of population trends characterized in the theory of demographic transition that establishes a pattern of changes in birth and mortality that inevitably leads in all societies to a time window with the minimal burden of demographic dependence. From the analysis of the census data at the provincial level in Argentina during the period of 1914-2040, situations are visible in which the burden of demographic dependence is characterized by marked interprovincial divergences. There are provinces that begin the period under study
\end{abstract}


with a low burden of demographic dependence, and remain in these positions over time, while in others the initial relative advantages fade, while the other provinces continually cope with the effects of this imbalance. demographic. The hypothesis is that the absence of the migratory component is the main limitation to explain these supposed irregularities by demographic theory. The relationship between the values of the provincial demographic dependency relationship and the migratory flows according to census years is presented.

Keywords: demographic burden; structure migrations by age; Theory of demographic transition.

\section{Resumo}

Inicia-se na explicação das tendências populacionais caracterizada pela teoria da transição demográfica que estabelece um padrão de mudanças em natalidade e mortalidade, o que provoca inevitavelmente em todas as sociedades uma janela temporal com mínima carga de dependência demográfica. A partir da análise dos dados dos censos provinciais na Argentina durante o período 1914-2040, podem se enxergar situações nas quais a carga de dependência demográfica se caracteriza por marcadas divergências interprovinciais. Existem províncias que iniciam o período de estudo com baixa carga de dependência demográfica, e se mantêm nestas posições ao longo do tempo, enquanto outras vão diminuindo as vantagens relativas iniciais, porém as restantes províncias suportam continuamente os efeitos deste desequilíbrio demográfico. A hipótese é que a ausência do componente migratório é a limitação principal para explicar estas supostas irregularidades por parte da teoria demográfica.

Apresenta-se a ligação entre os valores da relação de dependência demográfica provinciais e os fluxos migratórios conforme anos de censo.

Palavras-chave: carga demográfica; migrações; estrutura de idades; teoria da transição demográfica.

\section{Introducción}

La teoría más utilizada dentro de las ciencias demográficas es la llamada "teoría de la transición demográfica" (en adelante TTD) (LOPES PATARRA, 1973), formulada en 1909 por Adolphe Landry. A partir de la descripción de la evolución demográfica en los países desarrollados ${ }^{1}$, la TTD establece un patrón de cambios de la tasa de natalidad, mortalidad y crecimiento de la población que acompaña al proceso de desarrollo, y adicionalmente conlleva modificaciones de la estructura de edades de la población (ROA GARCÍA y CENDEJAS BUENO, 2007).

Se considera que en el pasado, las sociedades presentaban altos niveles de mortalidad y natalidad, pero las primeras contrarrestaban estas últimas, como consecuencia las tasas de crecimiento demográfico resultaban muy bajas o nulas. Posteriormente se ingresaría en una etapa denominada de transición incipiente, en donde se producen descensos en la tasa de mortalidad -principalmente infantil-, mientras la tasa de natalidad permanece en valores elevados, como resultado se obtiene un alto

1 El proceso demográfico de América Latina, se diferencia en relación con lo ocurrido en el mundo desarrollado en la velocidad de los cambios y en que este proceso es altamente heterogéneo entre los diferentes países que conforman la región, en concordancia con su gran diversidad social, cultural y étnica. 
crecimiento poblacional -bajo el supuesto de una población cerrada- (THOMPSON, 1929; LANDRY, 1934; GLASS, et al., 1965; NOTESTEIN, 1945; TABUTIN, 1980), así como también un aumento de la esperanza de vida, en un contexto de mejoras en las condiciones de vida y mediante la implementación de programas de salud públicoscomo ser campañas de prevención, el uso de vacunas y antibióticos, etc.- (ROA GARCÍA y CENDEJAS BUENO, 2007). Luego se ascendería a la etapa de transición plena, en donde el descenso de la natalidad se produce a ritmos superiores a los de la mortalidad, lo que implica que el crecimiento demográfico empiece a disminuir notablemente. Finalmente se alcanza el periodo denominado de transición avanzada, caracterizado por una relativa estabilidad de la mortalidad y la natalidad a niveles muy bajos, y produciéndose nuevamente una disminución del crecimiento demográfico.

Conforme se transita la TTD, considerada como un proceso inevitable al cual se encuentran sometidos todos los países $^{2}$, existiría una ventana temporal de aumento relativo de la población en edades activas, en comparación con los dependientes ancianos y jóvenes (UNFPA, 1998), por tanto la carga de dependencia demográfica se haría mínima.

La carga de dependencia demográfica es cuantificada mediante la relación de dependencia demográfica -en adelante RDD-, esta última es una medida de gran difusión. El cálculo de la RDD resulta de un cociente, el numerador está conformado por las personas consideradas como potencialmente inactivas - las poblaciones menores de 15 años y las de 65 años y más-, y el denominador lo constituye el grupo de los potencialmente productivos - la población comprendida entre 15 y 64 años-. Se destaca el uso de un criterio estrictamente biológico - división según grandes grupos de edad-, así como la ausencia de especificaciones teóricas, para discriminar a la población entre proveedores y consumidores netos (MANZANO y VELAZQUEZ, 2016).

Cabe destacar que la $\mathrm{TTD}^{3}$ al presuponer una población cerrada, deja fuera del análisis a la dinámica migratoria - todos los efectos y las consecuencias de las migraciones internas e internacionales-. Consideramos que esta limitación representa una notable insuficiencia analítica para poder contrastar la validez de la TTD, en mayor medida a un nivel inferior a la escala total del país. A partir de esta premisa surge el objetivo del estudio de este artículo, que se propone analizar la dinámica de la carga de

\footnotetext{
${ }^{2}$ Se supone que todas las poblaciones del mundo están expuestas a un único patrón de cambio, y por tanto, prevalece la tendencia a la igualación en todos los países. Considerando la dinámica demográfica dependiente únicamente del componente vegetativo. El análisis de datos poblacionales históricos, demuestra que los cambios demográficos de muchos países están lejos de poder adaptarse a la regularidad propuesta por la TTD en especial en el caso de los países de América Latina y el Caribe, en los que el factor migratorio presenta un rol importante generando diferenciaciones al interior de la región, con respecto al crecimiento poblacional y en las estructuras etarias de las poblaciones-(MANZANO, 2015).

${ }^{3}$ La división de Asuntos Económicos y Sociales de las Naciones Unidas estimó que "tal como está, la teoría de la transición demográfica es una interpretación de momentos decisivos de cambios en la evolución demográfica, más que un sistema de relaciones lógicamente coherentes y explícitas que proporcionen una base para deducciones pertinentes y predicciones de desarrollos futuros", concluyendo con el eufemismo de que "como teoría, es insatisfactoria" (ARANGO, 1980:172).
} 
dependencia demográfica, reflejada empíricamente a través del valor del indicador RDD, entre las provincias argentinas entre los años 1914 y 2040. Dicho periodo se aborda mediante los datos censales correspondientes a los censos realizados en los años 1914, 1947, 1960,1970, 1980, 1991, 2001 y 2010. Mientras que el intervalo restante 2010-2040-, surgen de las proyecciones elaboradas por el Instituto Nacional de Estadística y Censos basadas en los resultados definitivos del Censo Nacional de Población, Hogares y Viviendas 2010 (INDEC, 2013).

\section{Acerca del significado de la carga de dependencia demográfica.}

Como hemos mencionado anteriormente, la TTD establece que las sociedades evolucionan desde un régimen pre-moderno de alta natalidad y alta mortalidad, hacia un estado post-moderno en el cual ambos indicadores demográficos se presentan con valores bajos (KIRK, 1999). Es decir, se trata de un pasaje de elevados a bajos niveles de natalidad y de mortalidad (TORRADO, 1990; CEPAL-CELADE, 1993).

Se remarca una etapa de la TTD, en la cual debido al descenso sostenido de la fecundidad, la población infantil se reduce sustancialmente en términos relativos, mientras que aun la población mayor de edad sobre el total poblacional no es muy grande, y por tanto, la principal proporción de población se concentra en las edades activas (15 a 64 años). Estas condiciones permiten que los valores de RDD de los países desciendan hasta alcanzar los niveles más bajos que estos pueden experimentar en su historia demográfica (MARTÍNEZ GÓMEZ, 2013).

Los países en desarrollo experimentan un proceso de transición demográfica, en donde se avanza hacia niveles más bajos de mortalidad y fecundidad -si bien con claras contradicciones respecto a la TTD (MANZANO, 2016)-. A causa de estas tendencias demográficas en la literatura disciplinaria ha ido ganando importancia en las últimas décadas4 la relación entre cambio demográfico y crecimiento económico. Una de las posiciones considera que durante el periodo de descenso de la RDD, se supone que están dadas las condiciones demográficas para alcanzar el mayor crecimiento económico, así como además maximizar los niveles de bienestar de la población (CELADE, 2012), debido a la existencia de una mayor participación relativa de las personas que pueden proveerse por sí mismas. Esta ventaja se prolongaría hasta que el valor de la RDD vuelve a aumentar como consecuencia del incremento acelerado de la proporción de personas adultas mayores. Según Aguirre Pinto (2011:107) “...para aprovechar al máximo este beneficio el gobierno debe invertir en educación y en el desarrollo de recursos humanos5". Dentro de este enfoque se afirma que los efectos positivos de la

\footnotetext{
${ }^{4}$ Gran parte de la literatura que aborda esta relación, toma como referencias los países en desarrollo, remarcando la oportunidad histórica de convertir la transición demográfica en beneficio económico -una relación cuasi mecánica entre el valor de la RDD y el crecimiento económico. Entre los trabajos más citados: BLOOM, CANNING y SEVILLA, 2002; AGUIRRE PINTO, 2011; SAAD, MILLER, MARTÍNEZ y HOLZ, 2012.

${ }^{5}$ Esta afirmación tendría validez desde el punto de vista económico, sólo en el marco del paradigma de la teoría neoclásica, en el cual rige el supuesto de que la economía se encuentra constantemente en un nivel de
} 
menor carga demográfica sobre el crecimiento económico suelen darse vía tres mecanismos: aumento del peso relativo de la población potencialmente activa6; incrementos del ahorro agregado en la sociedad7; y crecimiento de la acumulación de capital humano8 (BLOOM y CANNING, 1999).

Al margen de esta posición, desde una perspectiva más amplia llama la atención la omisión respecto a la falta de consenso existente en la teoría económica en relación a cuales son los factores determinantes del crecimiento económico (DESTINOBLES, 2007 y ROSENDE, 2000). Por ejemplo los resultados de los tipos de modelos neoclásicos como los mencionados aplicados a América Latina -como en el caso de Taylor (1995) -, han sido desestimados por muchos autores, considerando que las pruebas de asociación no son robustas (GOLDBERGER, 1973; RAM, 1982; DEATON, 1992). Otras críticas, apuntan a la abstracción de la variabilidad existente en la tasa de crecimiento económico, la alta dependencia del ahorro externo en la región -baja proporción del ahorro local en el mercado financiero interno-, que no proporcionan un marco adecuado para comprender la relación entre las tasas de ahorro y la relación de dependencia demográfica de los jóvenes -tal como supone el modelo neoclásico-.

El uso de la edad como criterio para fijar la actividad económica (diferenciar activos o inactivos), utilizada por la RDD, este lejos de reflejar correctamente la carga real de dependencia económica, debido a que no toda la población potencialmente activa -el grupo poblacional de 15 a 64 años (en adelante PET)-, se encuentran ocupadas, como tampoco todas las personas mayores de 64 años se hallan fuera del mercado laboral (considerados sin ingresos, dada la falta de relación de contraprestación). Por tanto, el valor de la RDD expresa el potencial de la fuerza de trabajo máximo de un grupo etario especifico existente en un área geográfica determinada, sin diferenciar según las capacidades físicas, aprendizajes y destrezas, diferentes en las personas entre 15 y 64 años, que podría integrarse a las distintas actividades productivas (MANZANO, 2017 y PALACIO PRIETO et al., 2004). Además, cabe agregar entre sus carencias metodológicas y conceptuales, la diferenciación de ingresos mercantiles generados por fuera de las relaciones laborales (como ser ganancias por rentas, inversiones financieras, patentes, etc.), y distribución del ingreso o transferencias realizadas por parte de los privados y el Estado (transferencias monetarias a nivel intrafamiliar, transferencias en

pleno empleo (SHAIKH, 2001), por tanto, rige la premisa del desempleo como fenómeno de carácter voluntario.

${ }^{6}$ Consideran que se ampliarían las capacidades productivas, suponiendo que las fuerzas laborales gozaran de mayor salud y educación por lo que serían más productivas que en el pasado (ROA GARCÍA y CENDEJAS BUENO, 2007).

${ }^{7}$ Además el paradigma neoclásico sostiene que el incremento relativo de la población joven -aumento de la RDD de los jóvenes-, influye negativamente en los niveles de ahorro (COALE y HOOVER, 1958; LEFF, 1969; FRY y MASON, 1982).

${ }^{8} \mathrm{El}$ aumento de la esperanza de vida hace que el rendimiento a invertir en educación aumente (MEZTLER, 1995; KALEMLI-OZCAN, SORENSEN y YOSHA, 1999). Además, el descenso de la tasa de fecundidad provoca que los padres puedan dedicar más recursos por hijo, dotándoles de mayores niveles de educación y mejores cuidados médicos (ROA GARCÍA y CENDEJAS BUENO, 2007). 
concepto de seguros, asignaciones, pensiones, jubilaciones, etc.). Es decir, la RDD no aporta mucho más que una descripción demográfica de los cambios que se dan entre los grandes grupos de edad en una sociedad, al margen de los cambios estructurales y coyunturales que sufran tanto la demanda como la oferta de empleo, y de las personas desvinculadas de la actividad mercantil.

Cabe destacar que la oferta de empleo no se encuentra afectada solo por factores demográficos (FRIEDLAND y SUMMER, 2005), otra serie de factores son también determinantes (BARRIOBERO y FERNÁNDEZ, 2014), como situaciones de desempleo estructural "crónico", políticas activas de empleo, relaciones de carácter social y cultural, que se encuentran todas interrelacionadas.

Respecto al comportamiento de la demanda de empleo, se considera que intervienen múltiples factores económicos, entre los más relevantes, cabe mencionar la tecnológica aplicada a la producción e intercambio de cualquier tipo de bienes y servicios, y el nivel de actividad económica (MANZANO y VELÁZQUEZ, 2016).

El nivel de empleo9 de una economía resulta un dato cada vez más incierto, la evidencia empírica da cuenta de las deficiencias en el ajuste entre la oferta y demanda de empleo supuesta por la teoría económica clásica y neoclásica. Adicionalmente las expectativas salariales no se vinculan con los niveles formación de la oferta de mano de obra como en el pasado. Algunos autores en alusión a este nuevo contexto, destacan el desenlace del paradigma del trabajo asalariado, en donde las nuevas relaciones laborales con posibilidades de empleo estable se reducen continuamente (CABRALES, 2011).

\section{Las heterogéneas evoluciones de las cargas demográficas provinciales.}

En el presente apartado se llevara adelante un análisis de los cambios en la participación de los tres principales grupos de edad - población joven, en edad activa y adultos mayores-, según total país y a nivel provincial entre los años 1914 y 2040.

Como ya se ha explicitado anteriormente, según la TTD es esperable que las provincias evolucionen inicialmente a través de un descenso de la población infantil, durante este periodo el valor de RDD se reduce -debido a que se incrementa el porcentaje de la PET en el total poblacional, alcanzando el estadio de menor carga demográfica-, posteriormente comienza a incrementarse la proporción de personas adultas mayores, disipándose el beneficio de la menor carga demográfica -el valor de RDD vuelve a aumentar-.

A nivel total país la población mayor de 64 años representaba el 2,6\% en 1914, esta cifra se incrementa de manera continua en todos los periodos intercensales,

\footnotetext{
${ }^{9}$ Siendo una pregunta sumamente relevante heredado desde hace algo más de 200 años, sin embargo hasta el momento no existe consenso en relación a cómo se determina el nivel de empleo, ni tampoco respecto a sus determinantes entre las distintas escuelas económicas dentro del amplio y heterogéneo paradigma de las ciencias económicas-muy por el contrario, los supuestos que utilizan las principales escuelas económicas representan puntos de partida antagónicos - (MANZANO y VELÁZQUEZ, 2016).
} 
alcanzando el 10,2\% en el año 2010, acompañado de un nivel de variabilidad a lo largo de los ocho registros censales-cuantificado mediante el coeficiente de variación10-, de $37,2 \%$.

En el año 1914 la brecha interprovincial en el porcentaje de la población de 65 años y más era de 3,5 puntos porcentuales (en adelante p.p.) -diferencia que surge entre la provincia más envejecida, La Rioja con $4,2 \%$ de adultos mayores y la menos envejecida, Tierra del Fuego con solo 0,7\%-, pasando en el año 2010 a 12,6 p.p.-el valor máximo se produjo en el año 1991 correspondiente a un valor de 14,4 p.p. (entre CABA con 16,3\% y Tierra del Fuego 1,9\%) -. Lejos de presentar una mayor homogeneidad a nivel interprovincial tal como presupone la TTD, desde 1947 y hasta 204011 CABA se presenta como la jurisdicción más envejecida, y en el extremo opuesto, Tierra del Fuego se mantuvo desde 1914 y hasta 2020 con la menor proporción de adultos mayores, y para el periodo restante 2025-2040, fue reemplazada por la provincia de Santa Cruz.

Adicionalmente 6 de las 24 provincias no evidencian un menor porcentaje de adultos mayores en 1914, a diferencia de lo que sugiere el modelo de la TTD, sino en el año 1947, estas fueron: Catamarca, Jujuy, La Rioja, Salta, Santiago del Estero y Neuquén (cinco provincias de la región Noroeste y una de la patagónica).

En CABA se produjo el mayor envejecimiento durante el periodo 1914-2010 un incremento de 14,7 p.p. --, además presento como particularidad el valor más elevado de participación de adultos mayores en el año 2001. Asimismo Formosa se destacó por presentar la máxima dispersión, con un valor de coeficiente de variación de 49,0\% (ver Figura 01).

\footnotetext{
${ }^{10}$ El coeficiente de variación, permite comparar el nivel de variabilidad existente entre grupos de datos referidos a distintos sistemas de unidades.

${ }^{11}$ Los valores de los años quinquenales para cada una de las provincias del periodo 2010-2040, corresponden a las proyecciones elaboradas mediante el método de los componentes, que consiste en proyectar de forma independiente las variables determinantes de la dinámica poblacional: mortalidad, fecundidad y migración, a partir de una población base, se utilizaron los programas RUPEX y RUPAGG desarrollados por el U.S. Bureau of the Census (ARRIAGA, 2001; INDEC, 2013).
} 


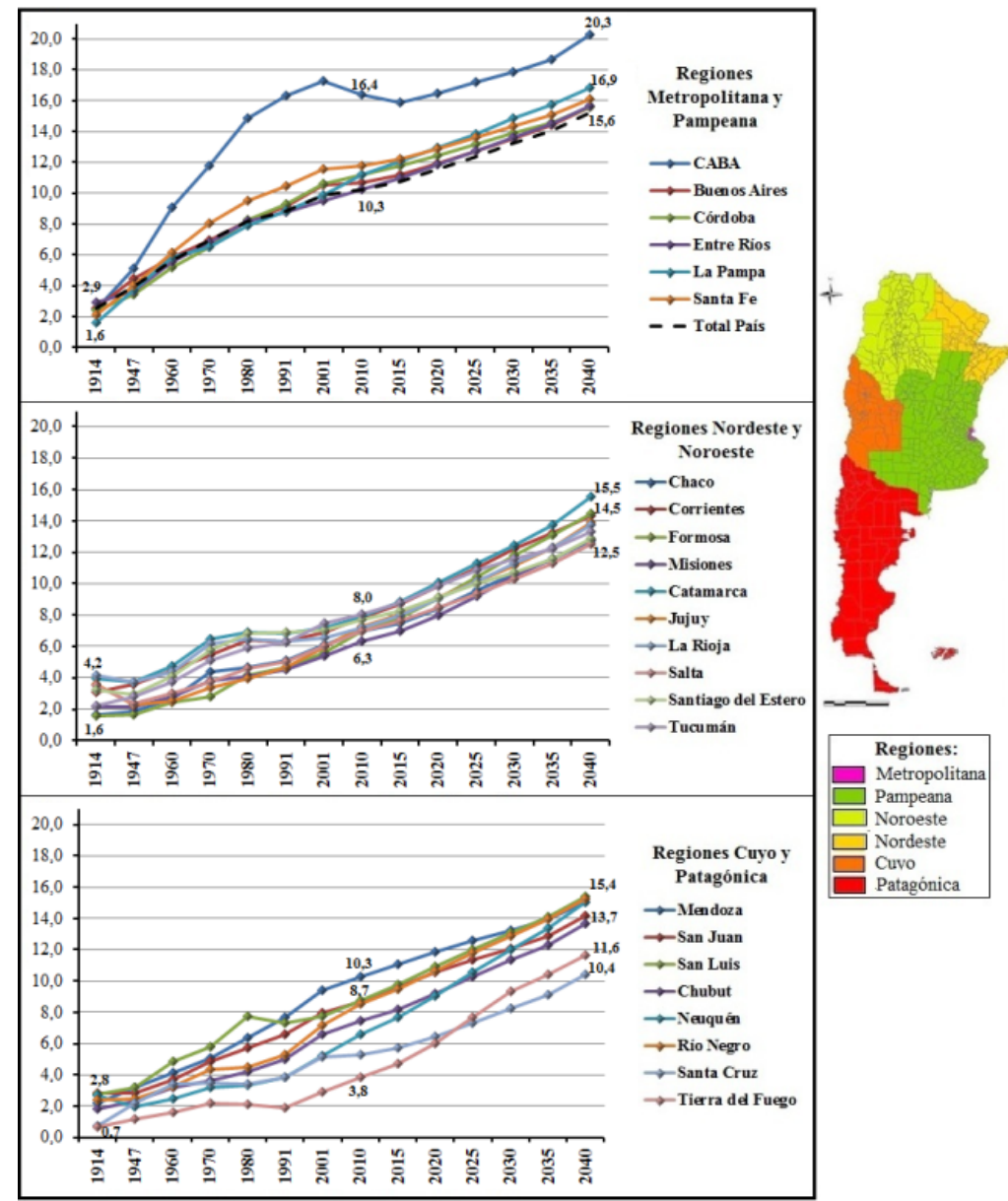

Figura 01: Porcentaje de mayores de 65 años y más, según provincias y regiones. Argentina (1914-2040)

Fuente: Elaboración personal en base a Censo Nacional de Población, Hogares y Viviendas 1914, 1947, 1960, 1970, 1980, 1991, 2001 y 2010, y estimaciones y proyecciones (INDEC, 2013).

La población menor de 15 años a nivel total país, paso de representar un porcentaje de $36,3 \%$ en el año 1914 a $25,5 \%$ en 2010 -disminución continua a nivel quinquenal con excepción del periodo intercensal 1980-1991-, una reducción relativa equivalente a 10,8 p.p., y presentó una variabilidad de 9,6\%.

En el año 1914 la brecha interprovincial en el porcentaje de la población de menores de 15 años era de 31,9 p.p. -diferencia que surge entre Santiago del Estero con 
44,0\% y Tierra del Fuego con solo 12,1\%-, pasando en el año 2010 a 16,2 p.p.-entre Misiones con $32,5 \%$ y CABA con $16,3 \%-$.

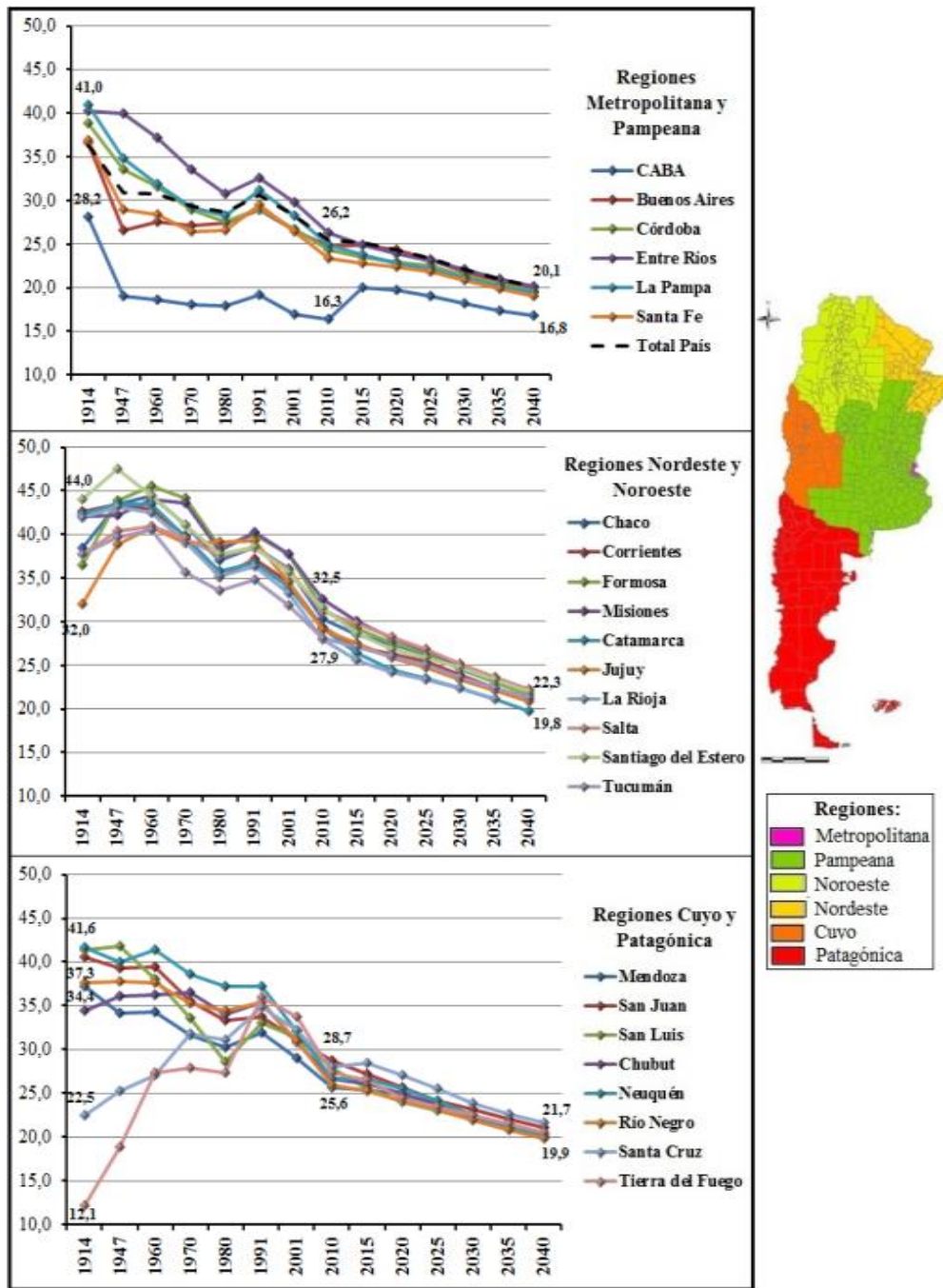

Figura 02: Porcentaje de menores de 15 años, según provincias y regiones. Argentina (1914-2040).

Fuente: Elaboración personal en base a Censo Nacional de Población, Hogares y Viviendas 1914, 1947, 1960, 1970, 1980, 1991, 2001 y 2010, y estimaciones y proyecciones (INDEC, 2013).

En solo nueve provincias coincidió el mayor porcentaje de población joven con el año 1914, acorde con la regularidad formulada por la TTD. Adicionalmente las 
provincias de Santa Cruz y Tierra del Fuego, presentan un comportamiento singular, las menores participaciones de jóvenes se hallan "contradictoriamente" en el año 1914. Respecto a la variabilidad de la participación relativa de los menores en el periodo 19142010 fue superior al total país en todas las provincias -se destaca Tierra del Fuego con $27,2 \%$, superando a la media nacional en 17,5 p.p. -, con tres excepciones, las provincias de Chubut, Misiones y Salta (ver Figura 02).

En los años censales 1914 y 1947 la jurisdicción con menor porcentaje de población joven fue Tierra del Fuego, luego es reemplazada por CABA que mantiene esta posición durante todo el periodo 1960-2040. Mientras que en la situación opuesta la mayor participación de población joven-, se destacan las provincias de la región noroeste y noreste, los máximos valor correspondieron a: Santiago del Estero en 1914 y 1947, Formosa 1960 y 1970, Jujuy en 1980, Misiones en el intervalo 1991-2020, y Salta en el periodo 2025-2040.

Resta analizar el grupo etario de los potencialmente proveedores de las personas en edad de trabajar. Existe total correspondencia entre este grupo de edad y el valor de la RDD -tal como se ha explicitado en el apartado previo-. Esto es, al momento de alcanzarse el máximo valor del porcentaje de PET en el total poblacional, se consigue el mínimo valor de la RDD -ambos indicadores cuantifican el nivel de carga de dependencia demográfica-.

En la Tabla 1 se presenta la evolución del porcentaje de la PET según la información de los años censales realizados desde 1914 hasta la fecha en Argentina.

A nivel total país el porcentaje de la PET fue de 61,2\% en 1914 y 64,3\% en 2010, el valor máximo entre ambos años censales correspondió a 1947, alcanzando un valor de 65,2\%, se destaca una abrupta disminución en 1991. Entre el máximo y mínimo valor durante los ocho registros censales considerados, la diferencia máxima fue de 4,7 p.p. y un nivel de variabilidad correspondiente a $2,4 \%$.

La brecha del porcentaje de la PET y la variabilidad de este indicador entre 1914 y 2010 a nivel provincial supera al valor del total país, con la única excepción que fue la provincia de Mendoza, se destaca Tierra del Fuego con valores máximos en la brecha de 20,3 p.p. y de coeficiente de variación de $10,9 \%$

Las provincias de Tierra del Fuego, Santa Cruz y CABA sobresalen por presentar en todos los años censales participaciones relativas de la población de 15 a 64 años mayores a la media nacional. 
Tabla 01: Porcentaje de población entre 15 y 64 años, según división provincial. Argentina (1914-2010).

\begin{tabular}{|c|c|c|c|c|c|c|c|c|}
\hline Regiones/Provincias & 1914 & 1947 & 1960 & 1970 & 1980 & 1991 & 2001 & 2010 \\
\hline Total País & 61,2 & 65,2 & 63,6 & 63,7 & 63,1 & 60,5 & 61,8 & 64,3 \\
\hline Metropolitana y Pampeana & 60,7 & 65,4 & 64,5 & 65,0 & 64,1 & 61,1 & 62,7 & 64,8 \\
\hline CABA & 69,3 & 75,8 & 72,3 & 70,1 & 67,3 & 64,6 & 65,9 & 67,2 \\
\hline Buenos Aires & 60,8 & 68,9 & 66,6 & 65,9 & 64,4 & 61,9 & 62,8 & 64,5 \\
\hline Córdoba & 58,7 & 63,0 & 63,3 & 64,5 & 64,2 & 61,6 & 62,7 & 64,5 \\
\hline Entre Rios & 56,8 & 56,4 & 57,2 & 59,7 & 61,1 & 58,7 & 60,7 & 63,5 \\
\hline La Pampa & 57,5 & 61,5 & 62,3 & 64,3 & 63,8 & 59,9 & 61,9 & 63,9 \\
\hline Santa Fe & 60,9 & 67,1 & 65,5 & 65,5 & 63,9 & 60,0 & 62,0 & 64,9 \\
\hline \begin{tabular}{|l|} 
Nordeste y Noroeste \\
\end{tabular} & 57,6 & 54,7 & 53,6 & 55,0 & 57,8 & 56,3 & 58,5 & 62,6 \\
\hline Chaco & 59,9 & 54,7 & 52,9 & 54,5 & 58,2 & 56,3 & 57,8 & 62,7 \\
\hline Corrientes & 54,3 & 52,9 & 52,7 & 54,7 & 58,5 & 56,5 & 58,6 & 62,8 \\
\hline Formosa & 62,0 & 54,4 & 52,0 & 53,0 & 57,3 & 55,4 & 56,7 & 61,5 \\
\hline Misiones & 55,8 & 55,6 & 53,2 & 52,6 & 57,7 & 55,3 & 56,8 & 61,2 \\
\hline Catamarca & 53,7 & 52,8 & 51,8 & 53,8 & 57,3 & 56,5 & 58,9 & 62,9 \\
\hline Jujuy & 64,4 & 58,9 & 56,6 & 57,6 & 57,0 & 56,1 & 59,5 & 63,7 \\
\hline La Rioja & 53,9 & 53,1 & 53,1 & 54,7 & 58,3 & 57,3 & 60,2 & 64,9 \\
\hline Salta & 58,7 & 57,2 & 56,0 & 56,7 & 57,8 & 56,5 & 58,1 & 61,8 \\
\hline Santiago del Estero & 52,8 & 49,5 & 51,5 & 53,1 & 55,4 & 54,6 & 57,3 & 60,7 \\
\hline Tucumán & 60,1 & 57,5 & 55,8 & 59,2 & 60,5 & 58,9 & 60,7 & 63,8 \\
\hline Cuyo y Patagónica & 64,5 & 63,4 & 61,5 & 62,0 & 63,3 & 60,1 & 62,1 & 65,5 \\
\hline Mendoza & 60,5 & 62,7 & 61,6 & 63,3 & 63,3 & 60,4 & 61,6 & 64,1 \\
\hline San Juan & 56,7 & 57,8 & 56,9 & 59,5 & 60,9 & 59,7 & 61,0 & 62,6 \\
\hline San Luis & 55,8 & 55,0 & 57,2 & 60,5 & 63,7 & 59,7 & 61,0 & 63,4 \\
\hline Chubut & 63,8 & 61,6 & 60,5 & 59,9 & 61,7 & 59,6 & 62,6 & 66,0 \\
\hline Neuquén & 55,7 & 58,0 & 56,2 & 58,2 & 59,5 & 59,0 & 62,7 & 66,8 \\
\hline Rio Negro & 60,0 & 59,8 & 59,1 & 60,5 & 61,0 & 59,3 & 61,8 & 65,5 \\
\hline Santa Cruz & 76,7 & 72,6 & 69,5 & 64,6 & 65,6 & 61,4 & 62,7 & 66,6 \\
\hline Tierra del Fuego & 87,2 & 79,9 & 71,0 & 69,8 & 70,6 & 62,2 & 63,3 & 68,8 \\
\hline
\end{tabular}

Fuente: Elaboración personal en base a Censo Nacional de Población, Hogares y Viviendas 1914, 1947, 1960, $1970,1980,1991,2001$ y 2010.

El valor promedio de RDD para el intervalo 1914-2010 a nivel total país fue de $59 \%$, se destacan cinco provincias por presentar valores inferiores a la media nacional en los ocho años censales entre 1914 y 2010, estas fueron: Tierra del Fuego, CABA, Santa Cruz, Buenos Aires y Santa Fe. Al interior de las diecinueve provincias restantes los valores medios más elevados de carga de dependencia demográfica del periodo 19142010 correspondieron a las provincias de las regiones nordeste y noroeste-con excepción de Tucumán-.

Como puede observarse en la Tabla 2 todas las provincias de las regiones metropolitana y pampeana aumentan su posición relativa entre ambos ranking. Por el contrario, al interior de las regiones Nordeste y Noroeste se destacan las provincias de Formosa y Jujuy con descensos relativos abruptos, Misiones y Salta con disminuciones 
relativas menos significativas, mientras que solo la provincia de La Rioja presento una mejora en términos relativos entre ambos ranking.

Tabla 02: Ranking de porcentaje de población entre 15 y 64 años y RDD, según división provincial. Argentina (1914-2010).

\begin{tabular}{|c|c|c|c|c|c|c|c|}
\hline \multirow[b]{2}{*}{ Regiones/Provincias } & \multicolumn{3}{|c|}{ Año 1914} & \multicolumn{3}{|c|}{ Promedio periodo $1914-2010$} & \multirow{2}{*}{$\begin{array}{c}\text { Cambio de } \\
\text { Posición } \\
\text { Relativa } \\
\end{array}$} \\
\hline & $\begin{array}{r}15 \text { y } 64 \\
\text { años (\%) }\end{array}$ & RDD & $\begin{array}{l}\text { Posición } \\
\text { Relativa }\end{array}$ & $\begin{array}{r}15 \text { y } 64 \\
\text { años (\%) }\end{array}$ & $\mathrm{RDD}$ & $\begin{array}{l}\text { Posición } \\
\text { Relativa }\end{array}$ & \\
\hline Total Pais & 61,2 & 63,5 & - & 62,6 & 59,0 & - & - \\
\hline Metropolitana y Pampeana & 62,5 & 59,9 & - & 64,4 & 54,6 & - & - \\
\hline CABA & 69,3 & 44,2 & 3 & 68,7 & 45,2 & 2 & 1 \\
\hline Buenos Aires & 60,8 & 64,4 & 8 & 64,2 & 55,3 & 4 & 4 \\
\hline Córdoba & 58,7 & 70,4 & 14 & 62,5 & 59,4 & 6 & 8 \\
\hline Entre Rios & 56,8 & 76,0 & 16 & 59,0 & 69,0 & 15 & 1 \\
\hline La Pampa & 57,5 & 74,0 & 15 & 61,4 & 61,8 & 9 & 6 \\
\hline Santa Fe & 60,9 & 64,1 & 7 & 63,2 & 57,1 & 5 & 2 \\
\hline Nordeste y Noroeste & 56,6 & 76,7 & - & 56,8 & 75,9 & - & - \\
\hline Chaco & 59,9 & 66,9 & 12 & 56,9 & 75,5 & 18 & -6 \\
\hline Corrientes & 54,3 & 84,2 & 21 & 56,1 & 78,0 & 21 & 0 \\
\hline Formosa & 62,0 & 61,2 & 6 & 56,3 & 77,5 & 20 & -14 \\
\hline Misiones & 55,8 & 79,1 & 18 & 55,7 & 78,8 & 22 & -4 \\
\hline Catamarca & 53,7 & 86,2 & 23 & 55,8 & 79,4 & 23 & 0 \\
\hline Jujuy & 64,4 & 55,2 & 4 & 59,1 & 69,3 & 16 & -12 \\
\hline La Rioja & 53,9 & 85,6 & 22 & 56,8 & 76,4 & 19 & 3 \\
\hline Salta & 58,7 & 70,3 & 13 & 57,7 & 73,0 & 17 & -4 \\
\hline Santiago del Estero & 52,8 & 89,5 & 24 & 54,2 & 84,6 & 24 & 0 \\
\hline Tucumán & 60,1 & 66,4 & 10 & 59,4 & 68,1 & 11 & -1 \\
\hline Cuyo y Patagónica & 59,1 & 69,1 & - & 60,9 & 63,4 & - & - \\
\hline Mendoza & 60,5 & 65,2 & 9 & 61,8 & 60,9 & 7 & 2 \\
\hline San Juan & 56,7 & 76,5 & 17 & 59,2 & 68,6 & 13 & 4 \\
\hline San Luis & 55,8 & 79,1 & 19 & 59,0 & 68,4 & 12 & 7 \\
\hline Chubut & 63,8 & 56,8 & 5 & 61,7 & 61,6 & 8 & -3 \\
\hline Neuquén & 55,7 & 79,5 & 20 & 59,5 & 68,6 & 14 & 6 \\
\hline Rio Negro & 60,0 & 66,7 & 11 & 60,7 & 64,4 & 10 & 1 \\
\hline Santa Cruz & 76,7 & 30,3 & 2 & 66,9 & 49,0 & 3 & -1 \\
\hline Tierra del Fuego & 87.2 & 14,7 & 1 & 70.6 & 41.2 & 1 & 0 \\
\hline
\end{tabular}

Fuente: Elaboración personal en base a Censo Nacional de Población, Hogares y Viviendas 1914, 1947, 1960, 1970, 1980, 1991, 2001 у 2010.

En la Figura 03 se aprecia la ausencia de convergencia en los valores de carga de dependencia demográfica para los censos realizados entre los años 1914 y 2010. Predominan los comportamientos heterogéneos por sobre las regularidades -en relación a las generalizaciones representadas en la TTD-:

- Santiago del Estero, Catamarca, Misiones y Corrientes partiendo de posiciones atrasadas, no sufrieron mejoras significativas, permaneciendo con mayores valores de carga demográfica respecto al resto de las provincias durante el periodo bajo estudio; 
- Las provincias de Formosa, Chaco y Salta presentaron bajos valores de cargas demográficas en el año 1914, finalmente se ubican entre las provincias con los valores más elevados de RDD;

-Jujuy y Tucumán en 1914 exhibieron valores bajos de carga demográfica, en los censos intermedios del periodo considerado pierden posiciones relativas, y en los últimos registros censales mejoraron su performance -no obstante sus situaciones relativas en el año 2010 son inferiores al año 1914-;

-La Rioja partió de una posición muy retrasada en 1914, se destaca en las regiones nordeste y noroeste que fueron las de mayor heterogeneidad, por llevar adelante un continuo descenso en su carga demográfica;

-Tierra del Fuego y Santa Cruz se iniciaron con una situación aventajada en 1914 y se mantienen entre las provincias con menores cargas de dependencia demográfica hasta finalizar el periodo;

-Rio Negro y Neuquén parten de las posiciones $\mathrm{N}^{\circ} 11$ y $\mathrm{N}^{\circ} 20$, respectivamente, en el año 1914, en la primera su ubicación relativa se mantuvo relativamente estable, mientras que en la segunda se evidencia un descenso en los valores de carga demográfica, no obstante hacia el año 2010 ambas se encuentran en similares posiciones relativas, en marcada mejoría respecto a 1914;

-Los casos de San Juan y San Luis se destacan por ubicarse en posiciones relativas elevadas en 1914 y 2010, mientras que entre dichos años censales se advierten marcadas disminuciones;

- Las provincias de Buenos Aires, Córdoba y La Pampa presentan una dinámica con una forma semejante a una "U"; y

-En los casos de CABA, Santa Fe, Entre Ríos Chubut y Mendoza predomino una relativa estabilidad, CABA se destaca con tan solo un cambio de posición relativa, mientras que Entre Ríos presento la mayor variabilidad entre estas cinco provincias. 


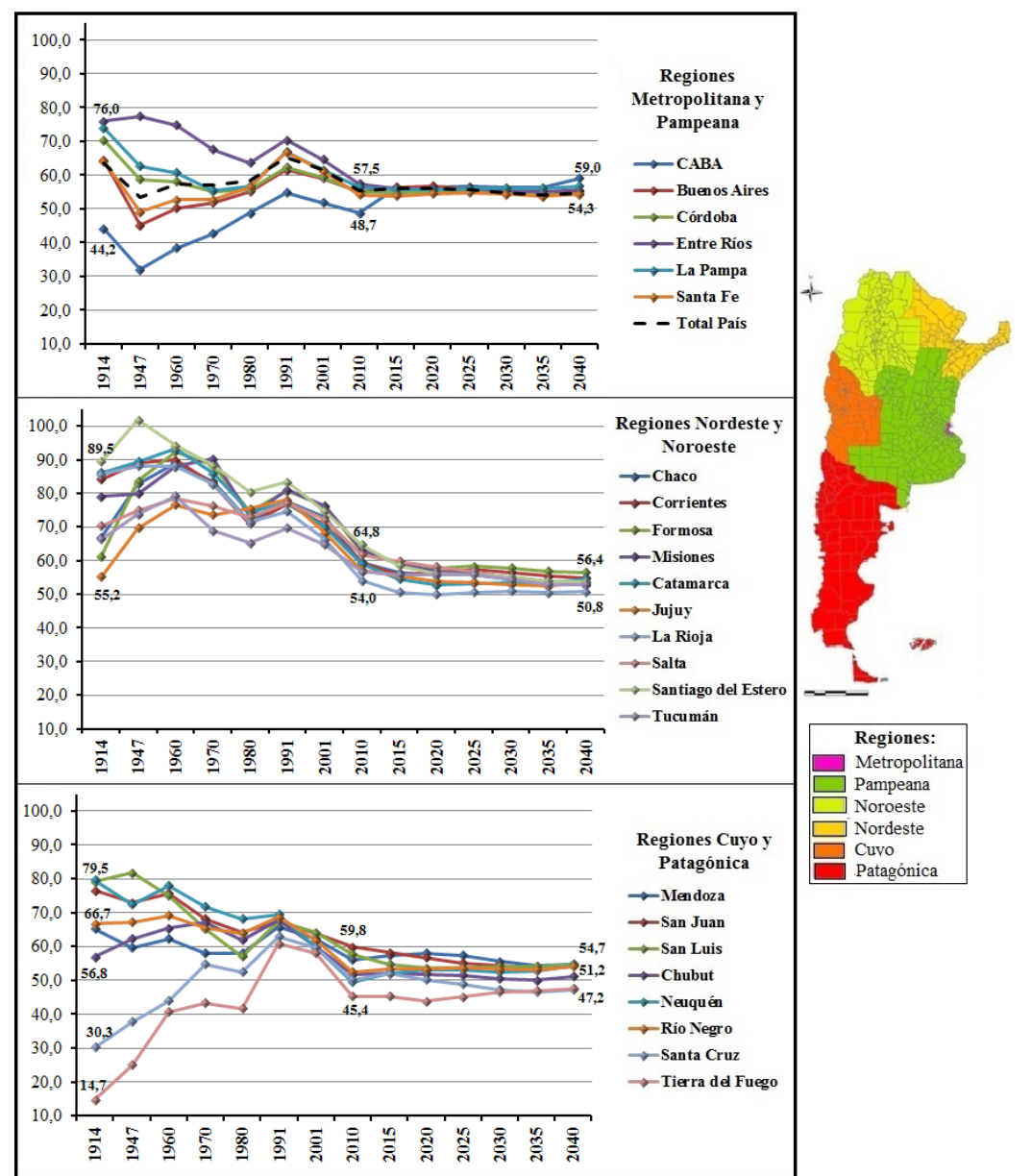

Figura 03: Evolución de la Relación de Dependencia Demográfica Total (por cien), según división provincial. Argentina (1914-2040).

Nota: $(*)$ Relación de dependencia total $=$ (población de menores de 15 años más la población de 65 y más años) / (población de 15 a 64 años)

Fuente: Elaboración personal en base a Censo Nacional de Población, Hogares y Viviendas 1914, 1947, 1960, 1970, 1980, 1991, 2001 y 2010, y estimaciones y proyecciones (INDEC, 2013).

\section{La incidencia de los flujos migratorios en la carga de dependencia demográfica}

Teniendo presentes las anomalías y divergencias destacadas en los apartados previos, respecto a la dinámica en los valores de carga de dependencia demográfica en cada provincia, en este apartado se adiciona una descripción de las dinámicas migratorias a nivel provincial -como ya se ha mencionado la TTD se circunscribe solo al 
componente vegetativo, es decir los cambios en la fecundidad y mortalidad-.Debido a las limitaciones de espacio, este análisis no será exhaustivo, se han seleccionado las provincias con comportamientos más erráticos en la evolución de su carga demográfica, están son:

- La Rioja: se destaca por su fuerte descenso en el valor de RDD;

- CABA: sostuvo bajos valores relativos de RDD;

- Formosa, Chaco y Salta: partieron de valores bajos de RDD, y disiparon estas ventajas relativas en el tiempo, ubicándose entre los valores más elevados de RDD;

- Santiago del Estero y Misiones: comenzaron con valores relativos altos de RDD y no logran revertir la adversidad; $y$

- Tierra del Fuego y Santa Cruz: iniciaron con baja carga de dependencia demográfica, y consiguen mantener esta ventaja relativa.

En la Tabla 4 se aprecia en primer lugar la dinámica peculiar de los flujos migratorios según su origen en el total del país. La participación relativa de los extranjeros alcanzó su máximo en el año 1914 -debido a los elevados volúmenes de los flujos migrantes de ultramar-. A partir de entonces, el porcentaje de extranjeros tuvo una tendencia descendente, alcanzando un peso relativo por debajo del $5 \%$ en la actualidad. Esto se evidencio también en el aumento de la población no migrante en el tiempo, representando el 78,6\% en el año 2010 -solo en el intervalo censal 1947-1960 se produjo una disminución-.

Cabe destacar el cambio en la composición de los extranjeros a partir del año 1991, pasando a ser mayoritarios los migrantes limítrofes en el total de los extranjeros. Además con posterioridad al año 1947, la participación relativa de los flujos de migrantes internos fue superior al aporte de los migrantes de origen externo a nivel total país.

La provincia de La Rioja tuvo el mayor porcentaje de población no migrante en 1914, esto se relaciona con haber sido la más envejecida y además era la quinta provincia con mayor participación de jóvenes, como resultado de esto su carga de dependencia demográfica era elevada -ocupo la posición relativa $\mathrm{N}^{\circ} 22$ en 1914 en el ranking de RDD-. A lo largo del transcurso del tiempo hasta alcanzar el año 2010, se produjo una disminución significativa de la participación de la población no migrante, esto implico por tanto, un aumento del peso relativo de los migrantes internos avanzando del puesto $\mathrm{N}^{\circ} 21$ al $\mathrm{N}^{\circ} 10$ entre 1914 y 2010-, también, si bien en menor medida, se incrementó el aporte de la población extranjera -pasando de la posición $\mathrm{N}^{\circ} 24$ a la $\mathrm{N}^{\circ} 17$ entre los años 1914 y 2010-. El ingreso de migrantes en edad de trabajar genero un descenso relativo del grupo de los adultos mayores y en menor medida de los personas menores de 15 años, en consecuencia se produjo una significativa reducción de la carga demográfica, ubicándose en la posición relativa $\mathrm{N}^{\circ} 7$ en el ranking de RDD en 2010. 
En 1914 la estructura demográfica de CABA presento un 40,5\% de población no migrante- a nivel interprovincial correspondió al puesto $\mathrm{N}^{\circ} 17-$, los extranjeros eran el 49,3\% del total -tercera posición relativa-, y la población restante correspondía a migrantes internos - posición relativa $\mathrm{N}^{\circ} 16-$, se destacó por tener los menores porcentaje de jóvenes -posición relativa $\mathrm{N}^{\circ} 22-$, y respecto al envejecimiento partió de la posición relativa $\mathrm{N}^{\circ} 12$. A esta situación le correspondió el tercer valor provincial más bajo de carga de dependencia demográfica. En el intervalo censal 1914-1947 se destacó un significativo incremento de los migrante internos -alcanzando la posición relativa $\mathrm{N}^{\circ} 4$-, posteriormente se mantuvo entre los primeros lugares en el ranking hasta el año 2010. Además conservo su posición entre las provincias con mayor participación de extranjeros -ocupo la primera posición en el año 2010-. El ingreso continuo de población extranjera y migrantes internos, principalmente en edad de trabajar, incidió en que los valores de carga demográfica permanezcan bajos en los 8 años censales -ocupo la primera posición en los años 1960,1970, 1991 y 2001-

Formosa en 1914 tuvo tan solo 30,6\% de población no migrante (puesto $\mathrm{N}^{\circ} 22$ ), un $23,9 \%$ de las personas eran migrantes internos (la cuarta provincia con mayor proporción), y el 45,5\% restante lo conformaban la población extranjera-posición relativa $\mathrm{N}^{\circ} 6$-. La alta incidencia de personas en edades activas, provoco que fuera la cuarta provincia menos envejecida, y le correspondiera un bajo nivel de carga demográfica -posición relativa $\mathrm{N}^{\circ} 6$ en el ranking de RDD en 1914-. Las proporciones de migrantes internos tuvieron un rápido descenso- en menor medida disminuyo la población extranjera-, en el año 1960 la población migrante fue de solo 35,4\%, y continuo descendiendo, en 1980 21,9\%, y hacia el 2010 solo represento 11,7\% del total poblacional. Por tanto, seguidamente la población no migrantes fue incrementándose producto de una mayor fecundidad y envejecimiento relativo-, como resultado el nivel de carga demográfica permaneció a partir de 1947 entre los más elevados.

La provincia de Chaco en 1914 estaba conformada por 46,3\% de migrantes internos -posición relativa $\mathrm{N}^{\circ} 1-, 32,4 \%$ de población no migrante -posición $\mathrm{N}^{\circ} 20$-, y $21,3 \%$ de extranjeros -posición $\mathrm{N}^{\circ} 14$ - La amplia presencia de población en edad activa posibilito formar parte de las provincias menos envejecidas -posición N²0 en 1914-. Se destaca una continua disminución de la proporción de migrantes internos, en los tres últimos años censales a un ritmo más acelerado, ubicándose en el año 1980 en el puesto $\mathrm{N}^{\circ}$ 9, en 1991 descendió a la posición $\mathrm{N}^{\circ} 15$, y a los años 2001 y 2010 les correspondieron las ubicaciones $\mathrm{N}^{\circ} 21$ y $\mathrm{N}^{\circ} 20$, respectivamente. La misma tendencia se presentó en el caso de los extranjeros, disminuyendo su proporción en relación al resto de las provincias, ocupando las posiciones $\mathrm{N}^{\circ} 16,18$ y 21 , en los años 1960, 1991 y 2010, respectivamente. Ante la ausencia de ingresos de personas en edad activa conjuntamente con una mayor fecundidad relativa, conllevo a una estructura demográfica con alta proporción de menores -en 1914 ocupo la posición $\mathrm{N}^{\circ} 12$, en 1960 el puesto $\mathrm{N}^{\circ} 2$, y si bien con cierta variabilidad se mantuvo entre las primeras posiciones en los años censales siguientes-, adicionalmente la población no migrante presento un mayor nivel de envejecimiento, por consiguiente la estructura etaria de 1947 dio cuenta de la mayor carga demográfica, en el ranking de RDD descendió hasta la posición $\mathrm{N}^{\circ} 19$, y se mantuvo en las últimas posiciones hasta el final del periodo considerado. 
Salta en 1914 estaba conformada por 78,1\% de población no migrante (posición relativa $\mathrm{N}^{\circ} 8$ ), $13,5 \%$ de migrantes internos (puesto $\mathrm{N}^{\circ} 11$ ), y solo 8,3\% de extranjeros (posición $\mathrm{N}^{\circ} 20$ ). Se destacaba por su alto envejecimiento (posición relativa $\mathrm{N}^{\circ} 4$ en 1914), y en el caso de los jóvenes su participación relativa era similar a la media nacional, el valor de RDD resultante de la conjunción de ambos grupos de edad correspondió a la ubicación $\mathrm{N}^{\circ} 13$. La proporción de migrantes internos comenzó a descender a partir de 1970, ubicándose en 1991 en el puesto $\mathrm{N}^{\circ} 17$ y en el año 2010 en la posición $\mathrm{N}^{\circ} 18$. Por el contrario, la participación de los extranjeros se incrementó entre 1914 y 1960, posteriormente se mantuvo relativamente estable, le correspondió la posición $\mathrm{N}^{\circ} 12$ desde 1980 a 2010. En consecuencia la posición relativa del grupo de los no migrantes tuvo un moderado descenso, sin embargo el mayor peso de población extranjera envejecida junto a la salida de grupos en edad de trabajar, incremento fuertemente la participación de las personas en edades extremas jóvenes y ancianos-, generando en consecuencia un aumento continuo de la carga de dependencia demográfica (pasando en el ranking de RDD de la posición relativa $\mathrm{N}^{\circ} 13$ a la No21 entre los años 1914 y 2010).

Santiago del Estero en 1914 presento una elevada proporción de población no migrante equivalente al 90,4\% -posición relativa $\mathrm{N}^{\circ} 4-$, en consecuencia las participaciones de los migrantes internos y externos fueron limitadas (en ambos casos ocuparon el lugar $\mathrm{N}^{\circ} 22$ en 1914). La ocurrencia de saldos migratorios negativos en el grupo en edad potencialmente activa, implico que fuera la provincia con mayor porcentaje de jóvenes, y asimismo se encontrara entre las más envejecidas, en consecuencia fue la provincia con mayor carga demográfica en 1914. No se produjeron incrementos de extranjeros, además el aporte de la migración interna fue ínfima, resultando una estructura demográfica predominantemente joven, correspondiente con persistentes valores elevados de RDD - en 1947 presentó una cifra record de 1,02-.

La población de Misiones en 1914 estaba compuesta por 38,0\% de extranjeros posición relativa $\mathrm{N}^{\circ} 7-, 13,1 \%$ de argentinos nacidos en otras provincias -posición relativa $\mathrm{N}^{\circ} 13-$, y $48,9 \%$ de población no migrante -puesto $\mathrm{N}^{\circ} 15-$. Partiendo de una estructura poblacional con alta participación de jóvenes -posición relativa $\mathrm{N}^{\circ} 4-$, y bajo nivel de envejecimiento relativo -puesto $\mathrm{N}^{\circ} 17$ - Esta última característica resulta menos relevante debido a que las brechas interprovinciales en el porcentaje de población de 65 años y más, son bajas a principios del siglo pasado. La vinculación entre los grandes grupos de edad en 1914 dio cuenta de una elevada carga de dependencia demográfica- el valor de la RDD se ubicó en la posición relativa $\mathrm{N}^{\circ} 18-$. Conforme transcurrió el tiempo, se incrementó el peso relativo de la población no migrante, en el año 1980 se ubicó en el puesto $\mathrm{N}^{\circ} 12$, y en el año 2010 asciende hasta la posición $\mathrm{N}^{\circ} 8$. La provincia se fue haciendo cada vez menos atractiva para los migrantes internos, en el año 1914 la población nacida en otras provincias representaba 13,1\% del total de los residentes (puesto $\mathrm{N}^{\circ} 13$ ), desde 1960 y hasta 2010 pivoteo entre las posiciones $\mathrm{N}^{\circ} 22$ y 23 . Los migrantes extranjeros en 1914 tuvieron una alta proporción en comparación con el resto de las provincias (puesto $\mathrm{N}^{\circ} 7$ ), esta situación fue mejorando llegando a la posición N4 en los años censales 1960 y 1970, luego descendió hasta la ubicación $\mathrm{N}^{\circ} 10$ en el año 2010. El aumento de la participación de la población extranjera no logro neutralizar la merma en los migrantes internos - se evidencio un aumento 
del peso relativo de los jóvenes, debido a la pérdida de población en edad de trabajar-, en consecuencia exhibió un aumento de la carga demográfica, ubicándose en las últimas posiciones a partir de 1970 en el ranking de RDD.

Tabla 04: Distribución porcentual de la población por condición migratoria, según división provincial. Argentina (1914-2010).

\begin{tabular}{|c|c|c|c|c|c|c|c|c|c|c|c|c|c|c|c|c|c|c|c|c|c|c|c|c|}
\hline \multirow{2}{*}{ Jurisdicciones } & \multicolumn{8}{|c|}{ No migrantes } & \multicolumn{8}{|c|}{ Migrantes internos ${ }^{(1)}$} & \multicolumn{8}{|c|}{ Migrantes Externos ${ }^{(2)}$} \\
\hline & \begin{tabular}{|l|l|}
1914 \\
\end{tabular} & 1947 & 1960 & \begin{tabular}{|l|}
1970 \\
\end{tabular} & 1980 & 1991 & 2001 & 2010 & 1914 & 1947 & 1960 & 1970 & 1980 & 1991 & 2001 & 2010 & 1914 & 1947 & 1960 & 1970 & 1980 & 1991 & 2001 & 2010 \\
\hline Total & 59,9 & 63,8 & 60,0 & 67,9 & 69,9 & 75,5 & 76,5 & 78,6 & 10,2 & 20,9 & 27,0 & 22,4 & 23,3 & 19,5 & 19,2 & 16,7 & 29,9 & 15,3 & 13,0 & 9,4 & 6,8 & 5,0 & 4,2 & 4,6 \\
\hline Buenos Aires & 59,3 & 59,2 & 45,4 & 56,1 & 56,5 & 66,9 & 68,7 & 67,4 & 6,6 & 22,5 & 38,1 & 32,2 & 34,8 & 26,9 & 25,8 & 26,4 & 34,1 & 18,3 & 16,5 & 11,7 & 8,6 & 6,3 & 5,5 & 6,2 \\
\hline CABA & 40,5 & 40,7 & 51,9 & 55,6 & 61,4 & 66,6 & 57,3 & 59,2 & 10,1 & 31,7 & 25,2 & 26,7 & 25,3 & 22,7 & 31,3 & 27,0 & 49,3 & 27,5 & 22,9 & 17,8 & 13,2 & 10,7 & 11,4 & 13,8 \\
\hline Catamarca & 91,2 & 87,8 & 90,4 & 88,3 & 87,6 & 86,1 & 85,4 & 89,6 & 6,6 & 10,9 & 8,5 & 11,3 & 11,9 & 13,4 & 14,2 & 9,9 & 2,3 & 1,3 & 1,0 & 0,5 & 0,5 & 0,4 & 0,4 & 0,4 \\
\hline Chaco & 32,4 & 56,2 & 68,3 & 74,6 & 80,2 & 85,9 & 89,5 & 91,0 & 46,3 & 34,0 & 25,9 & 21,1 & 17,3 & 12,8 & 9,7 & 8,4 & 21,3 & \begin{tabular}{l|l}
9,8 \\
\end{tabular} & \begin{tabular}{l|l}
5,9 \\
\end{tabular} & 4,2 & 2,4 & 1,4 & 0,8 & 0,7 \\
\hline Chubut & 32,9 & 43,4 & 59,5 & 63,0 & 64,5 & 66,0 & 69,9 & 67,3 & 21,2 & 36,6 & 21,1 & 22,9 & 23,9 & 25,2 & 23,4 & 26,0 & 45,9 & 20,0 & 19,4 & 14,1 & 11,5 & 8,8 & 6,7 & 6,7 \\
\hline Córdoba & 66,2 & 74,2 & 41,5 & 81,4 & 83,6 & 85,5 & 86,3 & 86,1 & 13,4 & 16,7 & 52,0 & 14,6 & \begin{tabular}{|l|}
13,9 \\
\end{tabular} & 13,0 & 12,4 & 12,3 & 20,5 & 9,1 & 6,5 & 4,0 & 2,5 & 1,5 & 1,3 & 1,6 \\
\hline Corrientes & 90,4 & 88,2 & 90,3 & 90,3 & 89,1 & 88,5 & 89,1 & 89,3 & 2,5 & 9,1 & 7,6 & 8,4 & 9,6 & 10,5 & 10,1 & 9,9 & 7,0 & 2,7 & 2,0 & 1,3 & 1,3 & 1,0 & 0,8 & 0,8 \\
\hline Entre Rios & 79,0 & 85,9 & 90,9 & 91,3 & 91,4 & 91,7 & 91,1 & 89,9 & \begin{tabular}{|l|}
4,0 \\
\end{tabular} & 8,8 & 5,9 & 6,5 & 7,1 & 7,3 & 8,2 & 9,2 & 17,0 & \begin{tabular}{|l|l}
5,3 \\
\end{tabular} & 3,2 & 2,2 & 1,5 & 0,9 & 0,7 & 0,9 \\
\hline Formosa & 30,6 & 55,4 & 64,6 & 70,1 & 78,1 & 83,1 & 85,0 & 88,3 & 23,9 & 15,2 & 12,8 & 14,0 & 10,9 & 10,1 & 10,5 & 7,5 & 45,5 & 29,4 & 22,6 & 15,9 & 11,0 & 6,8 & 4,5 & 4,3 \\
\hline Jujuy & 57,6 & 59,3 & 65,6 & 71,0 & 76,5 & 80,0 & 82,8 & 83,6 & 20,4 & 22,1 & 15,8 & 17,4 & \begin{tabular}{|l|} 
\\
\end{tabular} & 13,7 & 12,2 & 11,8 & 22,0 & 18,5 & 18,7 & 11,7 & 8,2 & 6,3 & 5,0 & 4,6 \\
\hline La Pampa & 32,0 & 65,2 & 71,9 & 76,3 & 77,2 & 76,8 & 75,5 & 76,9 & 31,5 & 21,4 & 19,9 & 18,6 & \begin{tabular}{|l|l|}
20,2 \\
\end{tabular} & 21,5 & 23,4 & 22,0 & 36,4 & 13,3 & 8,1 & 5,1 & 2,6 & 1,7 & 1,1 & 1,1 \\
\hline La Rioja & 91,9 & 87,1 & 86,4 & 86,7 & 86,0 & 82,8 & 80,6 & 80,8 & \begin{tabular}{|l|}
6,1 \\
\end{tabular} & 11,4 & 12,3 & 12,3 & 13,3 & 16,5 & 18,6 & 18,2 & 2,0 & 1,4 & 1,3 & 1,0 & 0,7 & 0,7 & 0,7 & 1,0 \\
\hline Mendoza & 55,7 & 71,6 & 74,9 & 77,6 & 80,2 & 82,8 & 85,2 & 85,8 & 12,4 & 16,7 & 15,5 & 16,0 & 14,3 & 12,8 & 11,1 & 10,2 & 31,8 & 11,7 & 9,6 & 6,4 & 5,5 & 4,4 & 3,6 & 4,0 \\
\hline Misiones & 48,9 & 62,1 & 68,8 & 75,3 & 80,4 & 85,2 & 88,2 & 88,8 & 13,1 & 11,6 & 8,4 & 7,7 & 7,9 & 7,8 & 7,2 & 7,0 & 38,0 & 26,2 & 22,8 & \begin{tabular}{|l|}
17,1 \\
\end{tabular} & 11,7 & 6,9 & 4,6 & 4,2 \\
\hline Neuquén & 47,6 & 63,3 & 68,3 & 66,6 & 65,2 & 62,6 & 66,5 & 67,2 & 6,3 & 23,1 & 18,5 & 23,2 & 25,1 & 28,0 & 26,4 & 26,3 & 46,1 & 13,6 & 13,2 & 10,1 & 9,6 & 9,4 & 7,2 & 6,5 \\
\hline Rio $\mathrm{Neg}$ & 40,5 & 57,8 & 57,2 & 59,6 & 60,3 & 62,7 & 68,3 & 68,7 & 24,3 & 25,3 & 23,1 & 24,3 & 26,0 & 25,7 & 22,9 & 23,7 & 35,2 & 16,9 & 19,7 & 16,1 & 13,7 & 11,7 & 8,8 & 7,5 \\
\hline Salta & 78,1 & 73,8 & 74,6 & 80,3 & 82,5 & 84,7 & 87,2 & 88,2 & 13,5 & 17,8 & 16,2 & 14,8 & \begin{tabular}{|l|}
13,7 \\
\end{tabular} & 12,1 & 10,1 & \begin{tabular}{|l|}
9,3 \\
\end{tabular} & 8,3 & 8,4 & \begin{tabular}{|l|l|}
9,3 \\
\end{tabular} & 4,9 & 3,8 & 3,2 & 2,7 & 2,4 \\
\hline San Juan & 79,8 & 83,7 & 85,1 & 88,3 & 89,9 & 91,5 & 92,4 & 92,6 & 6,5 & 9,7 & 9,3 & 7,9 & 7,7 & 6,9 & 6,6 & 6,5 & 13,8 & 6,7 & 5,5 & 3,8 & 2,4 & 1,5 & 1,1 & 0,9 \\
\hline San Luis & 79,9 & 82,4 & 82,9 & 82,2 & 81,9 & 76,5 & 73,4 & 72,8 & 11,6 & 14,4 & 14,5 & 16,2 & 16,9 & 22,1 & 25,3 & 25,9 & 8,6 & \begin{tabular}{|l|}
3,3 \\
\end{tabular} & 2,6 & 1,6 & 1,2 & 1,4 & 1,3 & 1,4 \\
\hline Santa Cruz & 15,7 & 22,6 & 33,8 & 37,4 & 42,9 & 48,5 & 53,5 & 50,5 & 16,9 & 38,8 & 27,9 & 35,2 & 35,9 & 35,8 & 34,5 & 39,3 & 67,4 & 38,6 & 38,4 & 27,4 & 21,2 & 15,8 & 12,0 & 10,1 \\
\hline Santa Fe & 50,9 & 69,0 & 76,2 & 77,9 & 80,8 & 83,5 & 85,5 & 86,0 & 14,0 & 17,9 & 14,8 & 16,3 & 15,9 & 14,7 & 13,3 & 12,9 & 35,1 & 13,1 & 9,0 & 5,8 & 3,3 & 1,9 & 1,2 & 1,2 \\
\hline Santiago del Estero & 90,4 & 87,0 & 90,7 & 89,6 & 89,4 & 89,9 & 89,9 & 90,0 & 6,0 & 11,2 & 8,1 & 9,6 & 10,1 & 9,8 & 9,8 & 9,7 & 3,6 & 1,8 & 1,3 & 0,8 & 0,5 & 0,3 & 0,3 & 0,3 \\
\hline Tierra del Fuego & 16,4 & 15,8 & 22,6 & 25,5 & 26,9 & 28,9 & 35,9 & 33,9 & 20,6 & 25,0 & 30,6 & 33,1 & 44,3 & 55,8 & 52,9 & 55,1 & 63,0 & 59,1 & 46,8 & \begin{tabular}{|l|}
31,4 \\
\end{tabular} & 28,8 & 15,3 & 11,1 & 11,0 \\
\hline Tucumán & 73,5 & 82,1 & 84,2 & 87,4 & 88,6 & 90,3 & 88,8 & 91,7 & 16,7 & 13,8 & 13,2 & 10,9 & 10,3 & 9,0 & 10,7 & 7,7 & 9,8 & 4,1 & 2,7 & 1,8 & 1,2 & 0,8 & 0,6 & 0,6 \\
\hline Jurisdicciones & \multicolumn{8}{|c|}{ Posición Relativa } & \multicolumn{8}{|c|}{ Posición Relativa } & \multicolumn{8}{|c|}{ Posición Relativa } \\
\hline Buenos A & 11 & 17 & 21 & 21 & 22 & 18 & 19 & 19 & 17 & 8 & 2 & 3 & 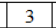 & 4 & 5 & 4 & 11 & 8 & 9 & 8 & 9 & 10 & 7 & 7 \\
\hline $\mathrm{CABA}$ & 17 & 22 & 20 & 22 & 20 & 19 & 22 & 22 & 16 & 4 & 6 & 4 & & 7 & 3 & 3 & 8 & 4 & 3 & 3 & 4 & 4 & 2 & 1 \\
\hline Catamarce & 2 & 2 & 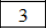 & 5 & 6 & 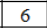 & 11 & 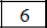 & 18 & 21 & 20 & 18 & 17 & 13 & 11 & 16 & 23 & 24 & 24 & 24 & 23 & 23 & 23 & 23 \\
\hline Chaco & 20 & 19 & 15 & 15 & 13 & 7 & 4 & 3 & & 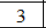 & & & & 15 & 21 & 20 & 14 & 14 & 16 & 15 & 16 & 18 & 18 & 21 \\
\hline Chubut & 19 & 21 & 18 & 19 & 19 & 20 & 18 & 20 & 5 & 2 & 8 & 7 & 7 & 6 & 7 & 6 & 5 & 6 & 7 & 7 & 6 & 6 & 6 & 5 \\
\hline Córdo & 10 & 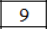 & 22 & 9 & 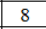 & 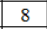 & 9 & 11 & 12 & 13 & 1 & 15 & 14 & 14 & 13 & 12 & 15 & 15 & 15 & 16 & 15 & 16 & 14 & 13 \\
\hline Corrie & 3 & 1 & 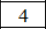 & 2 & 4 & 5 & 5 & 7 & 24 & 23 & 23 & 21 & 21 & 18 & 19 & 15 & 21 & 21 & 21 & 21 & 19 & 19 & 19 & 20 \\
\hline Entre Rios & 7 & 5 & 1 & 1 & 1 & 1 & 2 & 5 & 23 & 24 & 24 & 24 & 24 & 23 & 22 & 19 & 16 & 18 & 18 & 18 & 18 & 20 & 21 & 19 \\
\hline Formosa & 22 & 20 & 17 & 17 & 15 & 12 & 13 & 9 & 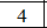 & 15 & 17 & 16 & 18 & 19 & 17 & 22 & 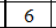 & 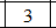 & 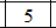 & 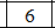 & 7 & 8 & 10 & 9 \\
\hline Jujuy & 12 & 16 & 16 & 16 & 17 & 15 & 14 & 14 & 7 & 9 & 12 & 10 & 12 & 12 & 14 & 13 & 13 & 7 & 8 & 9 & 10 & 9 & 8 & 8 \\
\hline La Pamt & 21 & 13 & 12 & 13 & 16 & 16 & 16 & 16 & 2 & 10 & 9 & 9 & 8 & 9 & 8 & 9 & 8 & 11 & 14 & 13 & 14 & 14 & 16 & 16 \\
\hline La Ric & 1 & 3 & 5 & 7 & 7 & 13 & 15 & 15 & 21 & 19 & 18 & 17 & 16 & 10 & 10 & 10 & 24 & 23 & 23 & 22 & 7 & 22 & 20 & 17 \\
\hline Mend & 1 & 11 & 10 & 12 & 14 & 14 & 12 & 13 & 14 & 14 & 13 & 13 & 13 & 16 & 15 & 14 & 12 & 13 & 11 & 11 & 11 & 11 & 11 & 11 \\
\hline Misiones & 15 & 15 & 13 & \begin{tabular}{|l|}
14 \\
\end{tabular} & 12 & 9 & 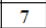 & 8 & 13 & 18 & 21 & 23 & 22 & 22 & 23 & 23 & 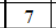 & 5 & 4 & 4 & 5 & 7 & 9 & 10 \\
\hline Neuquén & 16 & 14 & 14 & 18 & 18 & 22 & 21 & 21 & 20 & 7 & 10 & 6 & 6 & 3 & 4 & 5 & 4 & 10 & 10 & 10 & 8 & 5 & 5 & 6 \\
\hline Rio Negro & 18 & 18 & 19 & 20 & 21 & 21 & 20 & 18 & 3 & 5 & 7 & 5 & 4 & 5 & 9 & 8 & 9 & 9 & 6 & 5 & 3 & 3 & 4 & 4 \\
\hline Salta & 8 & 10 & 11 & 10 & 9 & 10 & 8 & 10 & 11 & 12 & 11 & 14 & 15 & 17 & 18 & 18 & 20 & 16 & 12 & 14 & 12 & 12 & 12 & 12 \\
\hline San Juz & 6 & 6 & 6 & 4 & 2 & 2 & 1 & 1 & 19 & 22 & 19 & 22 & 23 & 24 & 24 & 24 & 17 & 17 & 17 & 17 & 17 & 15 & 17 & 18 \\
\hline San Lui & 5 & 7 & 8 & 8 & 10 & 17 & 17 & 17 & 15 & 16 & 15 & 12 & 10 & 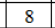 & 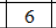 & 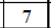 & 19 & 20 & 20 & 20 & 20 & 17 & 13 & 14 \\
\hline Santa Cruz & 24 & 23 & 23 & 23 & 23 & 23 & 23 & 23 & 8 & 1 & 4 & 1 & 2 & 2 & 2 & 2 & 1 & 2 & 2 & 2 & 2 & 1 & 1 & 3 \\
\hline Santa Fe & 14 & 12 & 9 & 11 & 11 & 11 & 10 & 12 & 10 & 11 & 14 & 11 & 11 & 11 & 12 & 11 & 10 & 12 & 13 & 12 & 13 & 13 & 15 & 15 \\
\hline Santiago del Ester & 4 & 4 & 2 & 3 & 3 & 4 & 3 & 4 & 22 & 20 & 22 & 20 & 20 & 20 & 20 & 17 & 22 & 22 & 22 & 23 & 24 & 24 & 24 & 24 \\
\hline Tierra del F & 23 & 24 & 24 & 24 & 24 & 24 & 24 & 24 & 6 & 6 & 3 & 2 & 1 & 1 & 1 & 1 & 2 & 1 & 1 & 1 & 1 & 2 & 3 & 2 \\
\hline Tucumán & 9 & 8 & 7 & 6 & 5 & 3 & 6 & 2 & 9 & 17 & 16 & 19 & 19 & 21 & 16 & 21 & 18 & 19 & 19 & 19 & 21 & 21 & 22 & 22 \\
\hline
\end{tabular}

Nota: (1) Nacidos en la Argentina que residen en una provincia distinta a la de su nacimiento. (2) Son la suma de los nacidos en países limítrofes y en países no limítrofes. Las dos categorías dan cuenta de la migración acumulada hasta cada fecha censal, independientemente de la antigüedad de la migración.

Fuente: Elaboración personal en base a Censo Nacional de Población, Hogares y Viviendas 1914, 1947, 1960, 1970, 1980, 1991, 2001 y 2010. 
Tierra del fuego en 1914 se destacó por presentar tan solo 16,4\% de población no migrante-posición relativa $\mathrm{N}^{\circ} 23$-, los migrantes internos aportaban el 20,6\% ubicación relativa $\mathrm{N}^{\circ} 6-$, mientras que los extranjeros alcanzaban el 63,0\% del total poblacional -puesto relativo $\mathrm{N}^{\circ} 2$ - La relación entre los grandes grupos de edad, presentaban una estructura demográfica con pesos relativos mínimos en los grupos extremos -en comparación con el resto de las provincias los porcentajes de jóvenes y adultos fueron los más bajos-, resultando, por tanto, la provincia con mayor proporción de población en edades potencialmente activas (15 a 64 años), análogamente exhibió la menor carga demográfica en 1914-. En su evolución mantuvo preponderancia la migración interna y externa, destacándose por el menor aumento relativo de población no migrante -ocupo en el puesto $\mathrm{N}^{\circ} 24$ hasta el año 2010-. De esta manera continua siendo la provincia menos envejecida, aunque se evidencio un leve aumento de la participación del grupo de menos de 15 años, este último fue neutralizado en gran medida debido a los bajos valores en las cargas demográficas al inicio del periodo en estudio, por tanto el valor de RDD permaneció entre los dos más bajos durante los ocho censos considerados.

Santa Cruz en 1914 estaba conformada por solo el 15,7\% de población no migrante-posición relativa $\mathrm{N}^{\circ} 24$-, el componente migratorio se distribuyó entre 16,9\% de migrantes internos y $67,4 \%$ de extranjeros -posiciones relativa $\mathrm{N}^{\circ} 8$ y 1 , respectivamente-. La baja incidencia de población de larga data y la elevada presencia de migrantes en edad de trabajar, era compatible con pesos relativos mínimos en los grupos de jóvenes y adultos mayores -posición relativa $\mathrm{N}^{\circ} 23$ en ambos indicadores-, en virtud de esto fue la segunda provincia correspondiente con menor carga de dependencia demográfica en 1914. Entre 1914 y 1947 se produjo un abrupto aumento de los migrantes internos, pese ciertas variaciones, se encontró entre las posiciones relativas más elevadas. La población no migrante alcanza el 50,5\% en 2010 , a pesar de este incremento solo ascendió una posición relativa -permaneciendo en el puesto $\mathrm{N}^{\circ} 23$ entre 1947 y 2010-, superando a Tierra del Fuego. Los extranjeros mantuvieron su tendencia inicial, destacándose entre las provincias con mayor participación de personas nacidas en otros países hasta el año 2010. El aporte sostenido de población en edad de trabajar, así como también el retorno del grupo de los adultos mayores, implico un incremento del peso relativo de los jóvenes, no obstante el valor de carga demográfica permaneció entre los más bajos a nivel interprovincial, los picos máximos se presentaron en los años censales 1970, 1991 y 2001, correspondientes a las posiciones relativas $\mathrm{N}^{\circ} 5,5$ у 6 , respectivamente

\section{Conclusiones}

Los resultados dan cuenta que el comportamiento de los grandes grupos de edad a nivel provincial estuvieron lejos de la tendencia a la convergencia interprovincial en los valores de carga de dependencia demográfica postulada por la TTD, asimismo tampoco se advierten fácilmente los estadios de bajas cargas de dependencia demografía a nivel provincial entre 1914 y 2040. Por el contrario, las descripciones dan cuenta del predominio de situaciones divergentes en la participación relativa del grupo en edad de 
trabajar (15 a 64 años), conjuntamente con condiciones de permanente ventajas en los valores de carga de dependencia demográfica en un grupo de provincias a costa de otras a lo largo del periodo.

De esta manera surgen contradicciones que impugnan las definiciones de la TTD en la evidencia empírica, como por ejemplo, la inexistencia de disminuciones en la población infantil (Santa Cruz y Tierra del Fuego), incrementos por periodos intermitentes de la población activa, disminuciones relativas del grupo de jóvenes inferiores al incremento de los adultos mayores, etc. Estas dos últimas situaciones se suceden de manera voluble en el tiempo entre las provincias.

Un rasgo de relevancia, adquiere las condiciones diferenciales entre las provincias al inicio del periodo bajo estudio - el III censo nacional realizado en el año 1914-, así se presentan provincias con elevada participación de los jóvenes que se mantienen a lo largo de los años censales, condicionándolas a elevados niveles de carga de dependencia demográfica (Santiago del Estero y Misiones), y provincias con mínima participación de jóvenes que se sostienen en el tiempo (CABA y Santa Fe). Así como también, situaciones provinciales en el año 1914 de alta participación de los adultos mayores (65 años y más), que se prolongan a lo largo de los años censales (Catamarca y Corrientes), mientras que otras provincias conviven en las condiciones contrarias (Tierra del Fuego, Santa Cruz y CABA). Se corroboran que valores bajos de dependencia demográfica son compatibles con elevados envejecimientos relativos - como se ha evidenciado en CABA, Santa Fe, La Pampa y Buenos Aires-, en cambio la situación contraria, adolecer de altos niveles relativos de jóvenes limita las posibilidades de disminución de la carga demográfica.

Para incrementar el nivel analítico resulto necesario incorporar la dinámica migratoria, factor ausente en los planteamientos de la TTD. Las tendencias de las migraciones internas e internacionales en las provincias difieren de los valores medios presentes a nivel total del país. Se destacan aquellas provincias que en 1914 presentaron una alta presencia de población no migrante, mayoritariamente concentrada en edad de trabajar, correspondiente a bajos niveles de carga demográfica, en tanto estás dinámicas migratorias se sostienen, ciertas provincias mantienen en el tiempo el beneficio de una menor carga demográfica respecto a las restantes (CABA, Santa Cruz y Tierra Del Fuego). Otro grupo de provincias también inicialmente fueron favorecidas ante la presencia de alta proporción de migrantes en edad activa, pero el flujo migratorio se interrumpe o incluso sufren pérdidas de población en edades laborales, por tanto la población no migrante es afectada por el envejecimiento, además esta situación suele agravarse debido a los mayores niveles de fecundidad, resultando en un deterioro de las ventajas relativas iniciales. En las provincias que se inician con valores medios o elevados de dependencia demográfica, no logran revertir estas condiciones, debido la imposibilidad de alcanzar el nivel de demanda de empleo necesario, así como tampoco garantizar las condiciones de calidad de vida adecuadas, padecen una continua sangría del grupo poblacional en edad activa en su estructura demográfica, siendo la excepción el caso de la provincia de La Rioja. 


\section{Referencias Bibliográficas}

ARANGO, J. La Teoría de la Transición Demográfica y la experiencia histórica. Revista Española de Investigaciones Sociológicas, N¹0, 1980, p. 169-198.

BARRIOBERO COLÁS, V; FERNÁNDEZ SIMÓN, B. Tasa de dependencia y crecimiento económico.¿Sólo el envejecimiento es importante?. XXI Encuentro de Economía Pública. Universidad de Girona, 2014.

BLOOM, D.E. y CANNING, D. Economic Development and Demographic Transition: The Role of Cumulative Causality. CAER II Discussion Paper 51, 1999.

BLOOM, D. E., CANNING, D., SEVILLA, J. Technological diffusion, conditional convergence, and economic growth. National Bureau of Economic Research, 2002.

CEPAL-CELADE. Población, equidad y transformación productiva. Libros de la CEPAL, $\mathrm{N}^{\mathrm{o}}$ 35. Santiago de Chile, Naciones Unidas, p. 215, 1993.

CEPAL. El bono demográfico: una oportunidad para avanzar en materia de cobertura y progresión en educación secundaria. Panorama social de América Latina, p. 143-169, 2008.

CELADE. Bono demográfco y envejecimiento: impactos sectoriales de la dinámica demográfca. CRIAD. Curso Regional Intensivo de Análisis Demográfca Modulo Población y Desarrollo. División de Población de la CEPAL, Santiago, 2012.

COALE, A; HOOVER, E. Population Growth and Economic Development in Low-Income Countries. Princeton: Princeton Univ. Press, 1958.

DEATON, A. Understanding Consumption. Oxford: Clarendon Pres, 1992.

DESTINOBLES, G. A. Introducción a los modelos de crecimiento económico exógeno y endógeno. [S.1.], Eumed.net, 2007.

INSTITUTO NACIONAL DE ESTADÍSTICA Y CENSOS. Estimaciones y proyecciones de población 2010-2040. Total del país. Serie de Análisis Demográfico, 35. Ciudad Autónoma de Buenos Aires, 2013.

KALEMLI-OZCAN, S., SORENSEN, B. y YOSHA, O. Risk sharing and industrial specialization: regional and international evidence. Mimeo., University of Houston, Federal Reserve Bank of Kansas City, and Tel Aviv University, 1999.

FRIEDLAND, R; SUMMER, L. Demography Is Not Destiny, Revisited. Washington, D.C: Center on an Aging Society, 2005.

FRY, M; MASON, A. Te Variable Rate-of-Growth Effect in the Life-Cycle Model. Economic Inquiry (20), 426-442, 1982.

GLASS, D; EVERSLEY, D. Population in history: essays in historical demography. Chicago, Aldine, 1965. 
GOLDBERGER, A. Dependency Rates and Savings Rates: Further Comment. American Economic Review (63), 232-233, 1973.

KIRK, D. Teoría de la transición demográfica en Población y Sociedad. Revista Regional de Estudios Sociales, №6 y 7, 1999.

LANDRY, A. La Révolution démographique. Études et essais sur les problèmes de population. París, Sirey, 1934.

LEFF, N. Dependency Rates and Savings Rates. American Economic Review (59), 886-896, 1969.

LOPES PATARRA, N. Transición demográfica: ¿resumen histórico o teoría de población? Demografía y Economía, v. 7, n. 1, 1973.

MANZANO, F. A. Bono Demográfico y Crecimiento Económico en los países de América Latina. Un abordaje crítico e interdisciplinario" Tesis doctoral inédita, Universidad Nacional de Córdoba, Córdoba. 2015.

MANZANO, F. A. La teoría de la transición demográfica y su inexactitud para America Latina. Periodo 1950-2000. Revista de Geografia (Recife), vol. 33, no 3. 2016.

MANZANO, F. A. La influencia de la edad en la inserción de trabajo como dependiente o independiente y su comportamiento a nivel espacial: Argentina (2001 y 2010). Ateliê Geográfico, v. 11, n. 1, p.06-23. 2017.

MANZANO, F. A; VELÁZQUEZ, G. A. La inexactitud de la relación de dependencia demográfica. Análisis del caso argentino (2001-2010). Cuadernos Geográficos, 55(2). 2016.

MARTÍNEZ GÓMEZ, C. Descenso de la fecundidad, bono demográfico y crecimiento económico en Colombia, 1990-2010. Serie de Estudios a Profundidad ENDS 1990-2010, Bogotá, Marzo. 2013.

NOTESTEIN, F. Population. The long view. En: SCHULTZ, E., (org.) Food for the World. Chicago, University of Chicago Press, p. 36-57. 1945.

PALACIO PRIETO, J. L. et al. Indicadores para la caracterización y el ordenamiento territorial. México: UNAM. 2004.

PINTO AGUIRRE, G. El bono demográfico una oportunidad de crecimiento económico. Revista Umbrales, vol. 22, p. 157-173. 2011.

RAM, R. Dependency Rates and Aggregate Savings: A New International Cross-Section Study. American Economic Review (72), 537-544. 1982.

ROA GARCIA, M. J.; CENDEJAS BUENOS, J. L. Crecimiento económico, estructura de edades y dividendo demográfico. Centro de Investigación y Docencia Económicas. Número 390. Toluca, México. 2007.

ROSENDE, R. Teoría del crecimiento económico: un debate inconcluso. Estudios de Economía, vol. 27, n. 1, p. 95-122, 2000. 
SAAD, P.; MILLER, T.; MARTÍNEZ, C. y HOLZ, M. Juventud y bono demográfico en Iberoamérica. Comisión Económica para América Latina (CEPAL-OIJ-UNFPA), 2012.

SHAIKH, A. La explicación de la inflación y el desempleo: una alternativa a la teoría económica neoliberal. Razón y Revolución (7), 2001.

TABUTIN, D. Problèmes de transition démographique. Francia, Université Catholique de Louvain. 1980.

TAYLOR, A. Debt, Dependence and the Demographic Transition: Latin America into the Next Century. World Development (23), 869-879. 1995.

THOMPSON, W. Population. American Sociological Review, vol. 34, № 6, p. 959-975, 1929.

TORRADO, S. Población y desarrollo: Metas Sociales y libertades individuales. (Reflexiones sobre el caso argentino). En: TORRADO, S. Política y Población en la Argentina. Claves para el debate. Buenos Aires, Ediciones de la Flor, 1990.

UNFPA. Shift to smaller families can bring economic benefits, News features. Fondo de Población de las Naciones Unidas, 1998.

\author{
Fernando Ariel Manzano \\ Doctor en Demografía por la Universidad Nacional de Córdoba. Licenciado \\ en Economía por la Universidad de Buenos Aires. Licenciado en Sociología \\ por la Universidad de Buenos Aires. \\ ORCID: https://orcid.org/0000-0002- 1513-4891 \\ Dr. Horacio Casco 4539 (1429) CABA. Rep. Argentina. \\ E-mail: fernandoarielmanzano@fch.unicen.edu.ar
}

Recebido para publicação em janeiro de 2019

Aprovado para publicação em maio de 2019 